\title{
Virtual Lab to run experiments of oscillations of a stretched rectangular membrane
}

\begin{abstract}
A Virtual Lab to run educational computer simulations of a vibrating membrane has been created. This educational virtual lab may be used to support some courses in the vibration engineering career. The module solves the $2 \mathrm{D}$ wave equation for a rectangular membrane which is shown on computer-screen vibrating according to data supplied by the user. The Virtual Lab makes the computations and renders on screen a 3D view of the vibrating membrane, which displays the normal modes of oscillation. A short theory is shown on screen while the simulation takes place, in this way the learning is fostered because the user verifies the theory with the simulation. Details on how to develop the simulation program are included, so that interested readers may create their own simulators. Some comments about the advantages of using computer simulation in education are included.
\end{abstract}

Keywords: Education, vibration engineering, oscillating membrane, computer simulation, wave equation.

LABORATORIO VIRTUAL PARA EJECUTAR EXPERIMENTOS DE OSCILACIONES EN UNA MEMBRANA RECTANGULAR ESTIRADA

\section{RESUMEN}

Se ha creado un laboratorio Virtual educacional para ejecutar simulaciones de computadora de una membrana vibrante. Este software puede utilizarse para reforzar algunos cursos en la carrera de ingeniería de vibraciones. El módulo de simulación ejecuta la solución de la ecuación $2 \mathrm{D}$ de onda para una membrana rectangular que aparece en la pantalla vibrando según datos ingresados por el usuario. El modulo hace los cálculos y muestra en pantalla una vista $3 \mathrm{D}$ de la membrana vibrante, que exhibe los modos normales de oscilación. Una teoría breve aparece en pantalla, de esta manera se promueve el aprendizaje pues el usuario verifica la teoría con el experimento. Se incluyen detalles sobre el desarrollo del programa de computadora, de modo que los lectores interesados puedan crear su propio simulador. De la experiencia docente del autor, se incluyen algunos comentarios sobre las bondades de usar simulación en computadora en el salón de clase.

Palabras clave: Educación, ingeniería de vibraciones, simulación, membrana vibrante, ecuación de onda.

\section{INTRODUCTION}

This paper is about vibrant surfaces, a theme dealt with in the university courses of oscillations and in vibration engineering. One of the simplest applications of vibrating surfaces is in the case of the vibration of the glass windows in a factory where high levels of noise are generated. As another example of rectangular vibrating membranes consider the glass windows and the windshield and rear window in an automobile. The computer simulation this paper deals with exactly meets this problem, because a glass window may be seen as a rectangular vibrating surface fixed at its extremes.

In the classroom, when dealing with the oscillations of a stretched rope, which is a bi-dimensional situation, the instructor makes a drawing on the blackboard of the normal modes of oscillation of that rope, and students easily understand those vibration patterns. The problem arises when studying the normal modes of oscillation of a stretched membrane. In this case -since the situation is tridimensional- most teachers never make a drawing of the vibrating membrane and students have only to resort to their imagination to figure out the motion of that surface.

Bear in mind that the oscillating membrane may be rectangular or circular, in the latter case the problem is even harder to envisage and hence to understand. This paper deals with the former case, namely the rectangular oscillating membrane.

Since the advent of computers and even more, since the development of high speed processors as well as visualization algorithms, computers have been used to improve education. Before computers, when the physics teacher spoke in classroom about vibration, students had to imagine the motion of a pendulum, a spring, etc. Then that student who was not able to imagine this motion, was condemned to poorly understand his instructor teachings and maybe at the end the student would pass the course and even learn, but without understanding.

Nowadays there exist a variety of commercial packages (software) where the user has only to enter her input data and the package renders the simulation on computer screen, however, developing the computer simulator is a very good practice and rewarding experience for whoever wants to master the art of

1 Master of Science. Profesor, Facultad de Ciencias Físicas - Universidad Nacional Mayor de San Marcos (UNMSM, Lima Perú) VirtualDynamics: Science \& Engineering Virtual Labs. E-mail: director@VirtualDynamics.Org 
scientific and engineering computer programming, including physics amateurs.

\section{THE MATHEMATICAL MODEL}

The oscillating membrane is a bi-dimensional system, hence the partial differential equation of two-dimensional wave motion applies (AlonsoFinn (1967), French (1974), O’Neil(2007), Vaughn (2007)), this is given by:

$$
\frac{\partial^{2} \psi}{\partial x^{2}}+\frac{\partial^{2} \psi}{\partial y^{2}}=\frac{1}{v^{2}} \frac{\partial^{2} \psi}{\partial t^{2}}
$$

and its solution, known as the wave function has the general form:

$$
\psi=\psi(x, y, t)
$$

Where $\mathrm{x}$ and $\mathrm{y}$ are space coordinates and $\mathrm{t}$ is the time.

The rectangular surface of sides $L_{x}$ and $L_{y}$ is fixed at its extremes and initially it is at rest (it has no velocity) with maximum amplitude Ao, then

$$
\begin{gathered}
\psi=0 \begin{cases}x=0, & x=L_{x} \\
y=0, & y=L_{y}\end{cases} \\
t=0: \quad \psi=A_{o}
\end{gathered}
$$

In a more sophisticated case, an initial velocity of the membrane may be included.

The mathematical solution of the differential equation (eq. 1) may be achieved by means of the method of Separation of Variables. The solution establishes the possible ways the membrane oscillates and it is given by

$$
\begin{aligned}
& \psi=A_{o} \operatorname{Sin}\left(k_{x} x\right) \operatorname{Sin}\left(k_{y} y\right) \operatorname{Cos}(\omega t) \\
& k_{x}=n_{x} \pi / L_{x} \\
& k_{y}=n_{y} \pi / L_{y} \\
& n_{x}, n_{y}=1,2,3, \ldots \\
& k^{2}=k_{x}^{2}+k_{y}^{2} \quad \omega=k v
\end{aligned}
$$

Where $n_{x}$ and $n_{y}$ are the normal modes of oscillation in the directions $x$ and $y$, respectively. Notice that in this case there is no damping. Since this work is a first approximation to the problem of vibrating surfaces, the effects of damping are not dealt with.
In order to confirm that eq.(2) is a solution of eq.(1), the interested reader may partially derivate eq.(2) and replace in eq.(1).

\section{THE VIRTUAL LABORATORY}

A virtual lab (a highly interactive and integrated computer program) to simulate in a computer an oscillating rectangular membrane fixed at its extremes has been created from scratch. The developed computer program (software) executes computations on the mathematical model (eq. 2) of the stretched rectangular membrane and then the results are subjected to a tri-dimensional visualization process (Gonzalez-Woods (1993), Foley, van Dam, Feiner, Hughes, (1996), Glaeser (1994), Thompson (1995)). All the stages of the computational process, this is, simulation and visualization, have been developed by the author of this report. Figure (1) shows the user interface of the reported module.

\subsection{Developing the membrane motion}

This section may be of importance to those students and teachers who would like to develop their own simulation module.

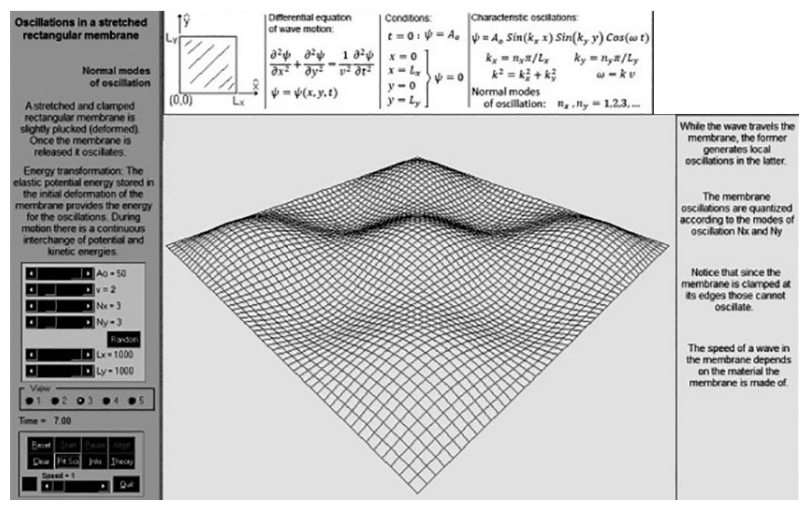

Figure 1. User interface of the reported virtual lab. It displays the parameters of the simulation as well as the vibrating membrane. It also shows simulation controls, and relevan concise theory. (Source: screenshot of the virtual lab created by the author of this report)

Figure 2 shows the flowchart of the computer program to develop and display the vibrating membrane on computer screen. The example in the flowchart is a rectangular membrane of sides $L x$ and Ly which have been fixed in 400 and 300 pixels, respectively. The maximum amplitude has been fixed in 25 pixels, the oscillation modes have been 
set to 2 and 3 respectively and, the time ranges from 1 to 250 units. In this example the membrane coordinates are varied in steps of Delta-X and Delta-Y, respectively.

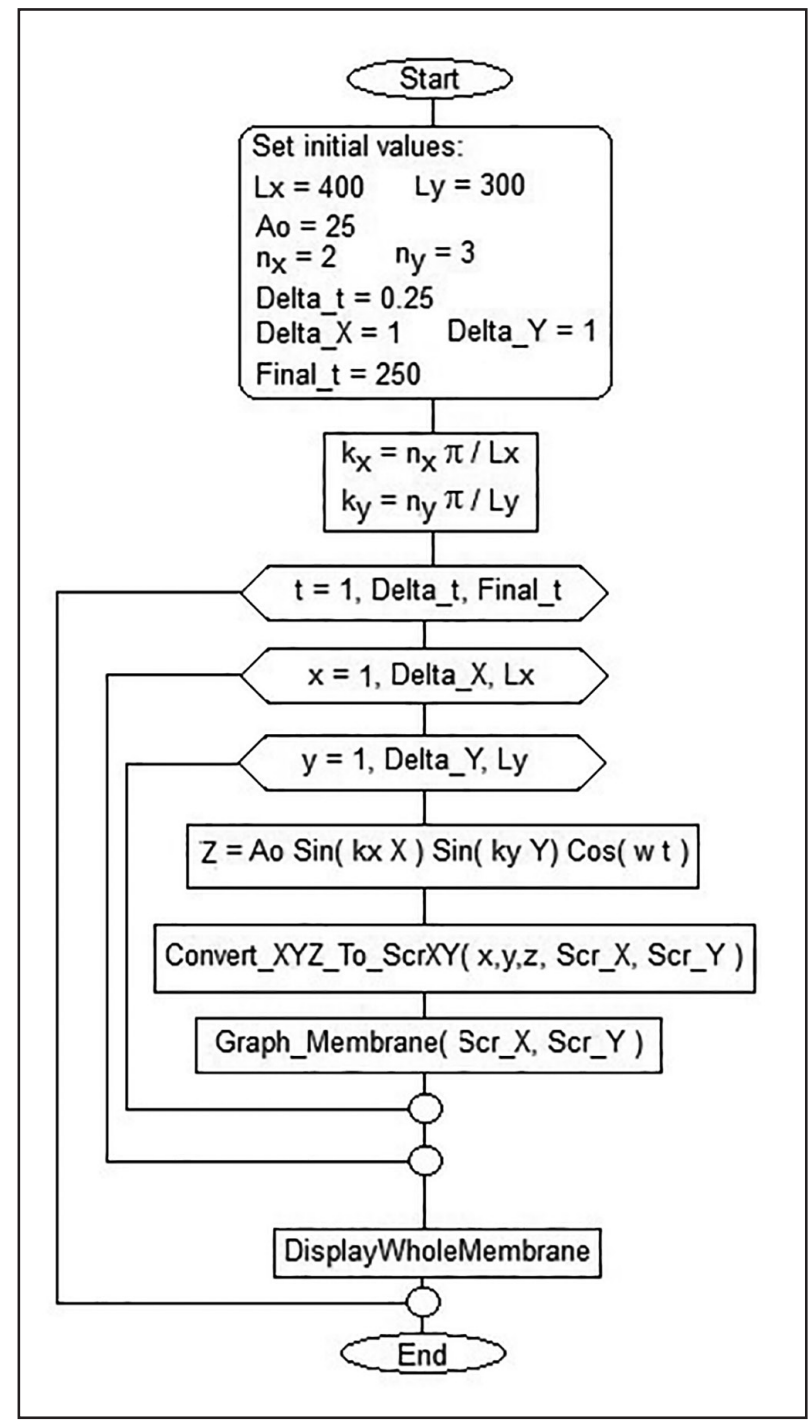

Figure 2. Flowchart of the computational process followed to display the oscillating membrane on computer screen. In this chart Convert $\mathrm{XYZ}$ To ScrXY is a computer graphics algorithm that calculates the $\bar{b}$ i-dimensional coordinates on screen of the 3D-points generated by the computations. (Source: flowchart created by the author of this report)

The mathematical model given by eq.(2) gives at every instant of time the height $Z$ at each point $(x, y)$ of the oscillating membrane resting on the $X Y$-plane. While the membrane oscillates its shape continuously changes, this means that for every instant of time the coordinates $(x, y)$ must be used in eq.(2) to determine the height $Z$ at that point. In this way a tridimensional point $(x, y, z)$ is obtained for every value of the time, which varies from Initial-t to Final-t in steps of Delta-t. Finally, the obtained tridimensional values $(x, y, z)$ of the membrane must be represented in a bi-dimensional form on computer screen, using any bi-dimensional representation of 3D-points. Being a student, this author created his own 2D-representation of 3D-points, based on principles of perspective and using geometry and trigonometry. In the literature the algorithms to project 3D-points onto the 2D-plane are known as imaging (perspective) transformations (GonzalezWoods (1993)).

In the flowchart the algorithm to represent on the (bi-dimensional) computer screen the tridimensional points $(x, y, z)$, is named Convert $x y z$ To_ScrXY, its input is the triad $(x, y, z)$ resulting from the computations and, its output are the screen coordinates (Scr_X, Scr_Y) of that point.

\subsection{The virtual experiment}

The user of the Virtual Lab is enabled to set the dimensions of the rectangular membrane as well as the normal oscillation modes to display while it vibrates on screen. As an example, figure (3) displays some of these natural oscillation modes. With the aim on easing learning, the virtual lab allows the user to choose among five possible ways of visualizing the oscillating membrane.

An interesting topic in the study of the vibrating rectangular membrane is that of the oscillation modes, until a few years ago students had to imagine these modes. Nowadays with the visualization facilities provided by computers students learn much more in shorter time and more easily.

\section{GENERALITIES ABOUT EDUCATIONAL VIRTUAL LABS}

This section includes some details about the development of educational virtual labs derived from the teaching experience of this author, who is a physics instructor at the university level teaching a variety of courses with the help of computer simulation. The here mentioned details have been implemented in the virtual module being reported.

\subsection{The module must include theory}

Theory associated to the experiment shown on computer screen must be included in the simulation module. This theory not only supports what is shown on screen but it also urges the student to try experiments to corroborate the theory. 

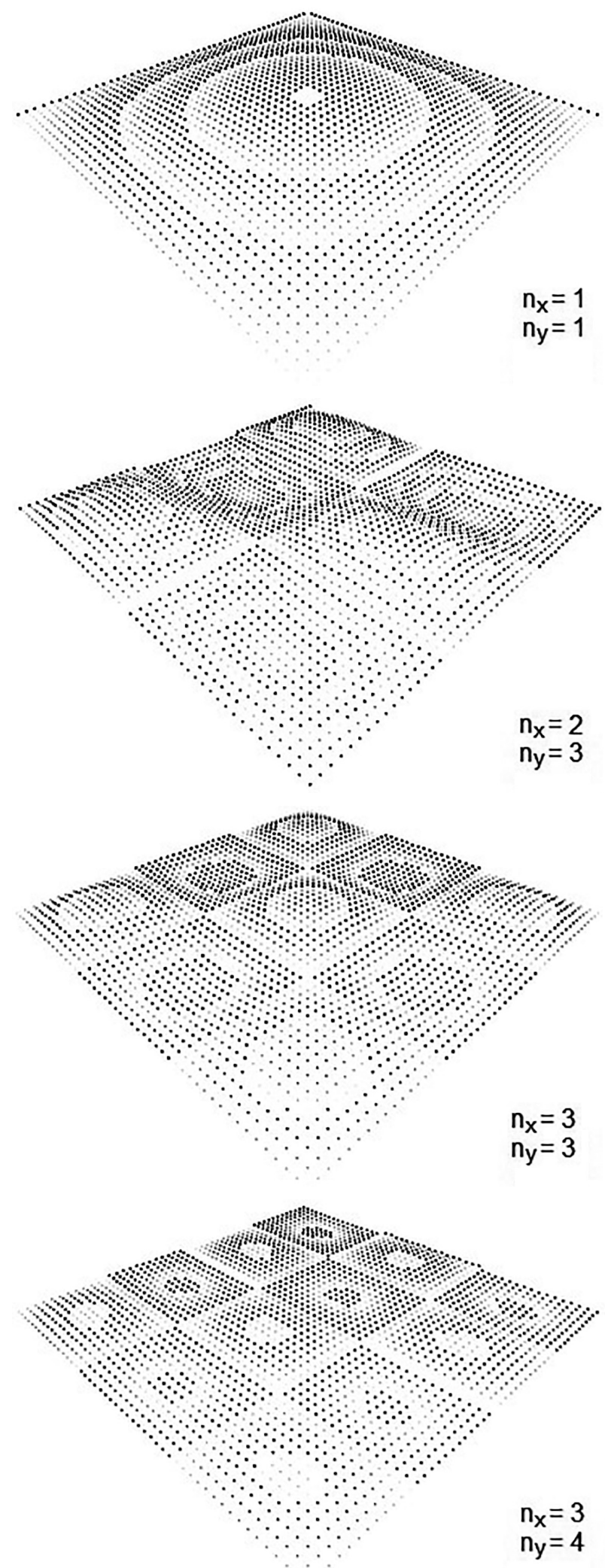

Figure 3. Four instances of the rectangular oscillating membrane. Here the visualization option most adapted to printing has been used. The module includes five visualization options so that the user can choose. (Source: screenshots of

the virtual lab created by the author of this article)

\subsection{Random input data}

Random input data implies experimenting in a short time with a very large number of input-data combinations, which is rewarding to the user of the virtual lab, because she feels that the computer -as it is expected- really makes it easier and indeed it helps to understand.

After witnessing the work of very many students who run virtual experiments of physics on university computers, this researcher has reached the conclusion that the manual input of data is simply excruciating to the user of the virtual Lab. Manual input of data is an activity that usually wearies the users and discourages their lab work. It seems to be that devising new combinations of parameters to run an experiment -whether in a traditional or in a virtual lab- may sometimes be dreadful and, this applies to students as well as to lab instructors. For this reason the educational simulation module must free the user of this stage as much as reasonably possible, without going to extremes.

It is the opinion of this researcher that computers must allow the opportunity of learning without any pain. The user must play with the simulation module while learning without any exaggerated effort.

Random input data is also useful when using a virtual lab to run instructive experiments to support the theory in the classroom. Sometimes students request to see additional examples of the topic covered in the theory class, in cases like these, the instructor can very quickly generate new examples by just clicking a "random" button.

Additionally, random input data fosters the learning because the user has to run experiments and verify results corresponding to data which are not his own. This random data input option avoids experimenting with any biased or subjective input data.

\section{WHY USING COMPUTER SIMULATION}

In real life when a stretched membrane -whether a drum or the glass in a window- is beaten it vibrates so quickly that human eyes are not able to watch the motion, hence being impossible to tell details about its vibration. In cases like these, interpretation of equations used to be the only alternative in the past. Today and thanks to computer-generated visualization it is no longer necessary to invest time and effort trying to interpret equations.

Even people with no training in mathematics or physics are now allowed to recognize the physics of some situations by just watching a detailed computer simulation. As an example consider the 
case of a psychologist who needs to understand the use of electrical impulses to thwart certain reactions to stimulus provided in some psychological experiments. Another example is the case of the lawyer who in a trial needs to understand the development of the collision of automobiles in a car accident.

Virtual labs like the one described in this report are a great aid to Physics amateurs because these people now can appreciate physics while enjoying it and learn from virtual experiments at the same time and, the most important, at their own pace. As a consequence learning becomes easier and amenable, because interested people may run a virtual experiment and learn from it.

\subsection{The advantage of virtual experiments}

Virtual labs allow simulating dangerous experiments such like the motion of a projectile shot by cannon. Usually in this experiment the objective is to watch the parabolic orbit described by the projectile. In a traditional lab a shooting device must be used to execute this experiment, but this exposes the students to accidents and the projectile travels so quick that the parabolic trajectory is never visualized. The only alternative is computer simulation, which may leave a track on computer screen and allows watching in a short time many instances of the parabolic flight of the projectile.

The situation of the orbit followed by a flying projectile is even more delicate when the objective is studying the influence of the air resistance to the motion of the projectile. In this case the exact way the air resistance alters the orbit of the projectile can be appreciated only by computer simulation.

Whoever has made the experiment of a freely falling object in a conventional lab, knows that it is impossible to obtain an accurate measure of the different distances the object falls down each second. This occurs because in real life the time elapses very fast and the acceleration of the gravity on earth is rather high. In a Virtual lab both the evolution of time and the acceleration of the gravity can be easily controlled by the user, hence a virtual experiment allows measuring the above mentioned distances and even plotting a graph at the same time.

Computer simulation followed by visualization is also useful because it helps to discard some results or situations that though they are allowed by mathematics they are at the same time forbidden by physics. As an example consider the membrane that is mathematically allowed to stretch out beyond its dimensions. If it weren't by computer visualization, the mathematical result would be accepted, however, when a physics-trained person watches the simulation he knows that case must be discarded from the set of realistic solutions.

Virtual experiments strongly depend on mathematical models. This means that the best visualization algorithms and the more powerful computers may be useless if the mathematical model used to make a computer simulation does not reflect with enough accuracy the actual phenomenon.

The trivial and obvious advantage of virtual labs is that they do not require personnel to clean and to prepare the experiment room and, to handle the equipment before and after the experiment.

The module reported in this paper has been included in the Physics Virtual Lab (PVL) (Montenegro $(2005,2009))$, which currently is a collection of 191 intuitively-easy-to-use physics simulation modules developed by this author.

\section{CONCLUSIONS}

A virtual lab to computer-simulate the vibrations of a rectangular membrane fixed at its extremes has been created. The virtual lab not only makes the calculations but it also displays the oscillating membrane on computer screen, making it easier for the student to grasp the knowledge about this problem.

Details on the development of the computer simulator have been described so that interested readers may be able to create their own computer program.

Some comments based on the experience of the author on the creation and on the use of educational computer simulators have been exposed.

\section{REFERENCES}

[1] Alonso M, Finn E. J., (1967), Fundamental University Physics, Vol II, USA: AddisonWesley.

[2] French A. P., (1974), Vibrations and Waves, New York, USA: W.W. Norton \& Co.

[3] O'Neil P.V., (2007), Advanced Engineering Mathematics, Canada: Nelson Ed.

[4] Vaughn M.T., (2007), Introduction to Mathematical Physics, Wiley

[5] Gonzalez R.C., Woods R.E., (1993), Digital Image Processing, Addison-Wesley 
[6] Foley, van Dam, Feiner, Hughes, (1996), Computer Graphics, USA: Addison-Wesley

[7] Glaeser G., (1994), Fast Algorithms for 3D-Graphics, New York, USA: Springer-Verlag

[8] Thompson N., (1995), Animation Techniques in Win32, New York, USA: Mc Graw Hill

[9] Montenegro J. J., (2005) The Physics Virtual Laboratory 109, PVL-109. Third International.
Conference on Multimedia and Information \& Comm. Technologies in Educ (m-ICTE 2005), Caceres, Spain.

[10] Montenegro J. J., (2009) Physics Virtual Laboratory 145, PVL-145. V International Conference on Multimedia and ICT in Education (m-ICTE 2009), Lisbon, Portugal. 